\title{
PSAPP mice exhibit regionally selective reductions in gliosis and plaque deposition in response to S100B ablation
}

\author{
Emily Roltsch', Leigh Holcomb ${ }^{2,3}$, Keith A Young ${ }^{2,3}$, Alexander Marks ${ }^{4}$, Danna B Zimmer ${ }^{*}$
}

\begin{abstract}
Background: Numerous studies have reported that increased expression of S100B, an intracellular $\mathrm{Ca}^{2+}$ receptor protein and secreted neuropeptide, exacerbates Alzheimer's disease (AD) pathology. However, the ability of S100B inhibitors to prevent/reverse AD histopathology remains controversial. This study examines the effect of S100B ablation on in vivo plaque load, gliosis and dystrophic neurons.

Methods: Because S100B-specific inhibitors are not available, genetic ablation was used to inhibit S100B function in the PSAPP AD mouse model. The PSAPP/S100B ${ }^{-/}$line was generated by crossing PSAPP double transgenic

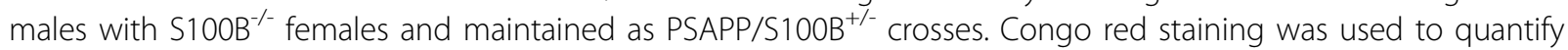
plaque load, plaque number and plaque size in 6 month old PSAPP and PSAPP/S100B ${ }^{-/}$littermates. The microglial marker Ibal and astrocytic marker glial fibrillary acidic protein (GFAP) were used to quantify gliosis. Dystrophic neurons were detected with the phospho-tau antibody AT8. S100B immunohistochemistry was used to assess the spatial distribution of S100B in the PSAPP line.
\end{abstract}

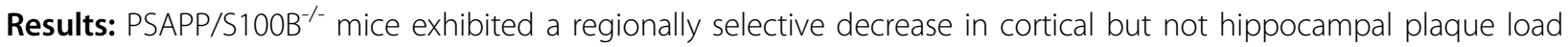
when compared to PSAPP littermates. This regionally selective reduction in plaque load was accompanied by decreases in plaque number, GFAP-positive astrocytes, Iba1-positive microglia and phospho-tau positive dystrophic neurons. These effects were not attributable to regional variability in the distribution of S100B. Hippocampal and cortical S100B immunoreactivity in PSAPP mice was associated with plaques and co-localized with astrocytes and microglia.

Conclusions: Collectively, these data support S100B inhibition as a novel strategy for reducing cortical plaque load, gliosis and neuronal dysfunction in AD and suggest that both extracellular as well as intracellular S100B contribute to AD histopathology.

\section{Background}

$\mathrm{S} 100 \mathrm{~B}$, a member of the $\mathrm{S} 100$ protein family, is expressed predominantly in astrocytes and functions as both an intracellular $\mathrm{Ca}^{2+}$ receptor and an extracellular neuropeptide [1-3]. The term S100 to refers to the solubility of these 10,000 molecular weight proteins in saturated ammonium sulfate [4]. S100 proteins are distinguished from other members of the S100/calmodulin/troponin superfamily of EF-hand $\mathrm{Ca}^{2+}$ binding proteins by their $3 \mathrm{D}$ structure and highly conserved 14

\footnotetext{
* Correspondence: dzimmer@cvm.tamu.edu

'Department of Veterinary Pathobiology, Texas A\&M University, College Station, TX, USA

Full list of author information is available at the end of the article
}

amino acid $\mathrm{Ca}^{2+}$ binding loop [5]. Upon binding $\mathrm{Ca}^{2+}$, S100 proteins undergo a conformational change which exposes a hydrophobic patch necessary for interacting with numerous intra- and extracellular protein targets and subsequent exertion of their biological effects $[5,6]$. Over 20 intracellular targets have been reported for S100B suggesting that it regulates a large number of diverse cellular processes, including energy metabolism, cell proliferation, cytoskeletal organization, $\mathrm{Ca}^{2+}$ homeostasis and signal transduction pathways. The extracellular effects of $\mathrm{S} 100 \mathrm{~B}$ are concentration dependent; nanomolar S100B levels beneficially promote neuronal survival while micromolar levels detrimentally promote apoptosis [7-9]. S100B's extracellular effects are thought 
to be mediated by the receptor for advanced glycation end products (RAGE) $[7,8]$. S100B release/secretion is regulated by forskolin, lysophosphatidic acid, serotonin, glutamate, IL-6 $\beta$, metabolites and the neurotoxic $A \beta$ peptide [10-14] as well as being gender- and age-dependent [15]. Increased S100B levels are associated with a variety of neurological disorders including Alzheimer's disease (AD), multiple sclerosis, amyotrophic lateral sclerosis, schizophrenia, epilepsy, alcoholism, drug abuse, hypoxia and traumatic brain injury $[1-3,16,17]$.

Altered S100B function is associated with AD pathobiology. The clinical presentation and pathology of early- and late-onset AD include early disturbances in $\mathrm{Ca}^{2+}$ homeostasis followed by inflammation, neurodegeneration, senile plaques comprised of aggregated amyloid $\beta$ (A $\beta)$ peptide, intracellular neurofibrillary tangles comprised of aggregated hyperphosphorylated tau, and ultimately cognitive dysfunction [18-21]. In human autopsy specimens, the highest levels of S100B expression are observed in the most severely affected regions and S100B associates with plaques $[3,22,23]$. Serum/CSF S100B levels inversely correlate with cognitive function, i.e patients with lower S100B levels exhibit lower Clinical Dementia Rating scores and higher Mini-Mental State Examination scores [24]. In addition, the rs2300403 single nucleotide polymorphism (SNP) in the S100B gene is associated with low cognitive performance, dementia and AD [25]. While the cellular events/molecular mechanisms whereby S100B contributes to AD pathobiology have not yet been elucidated, $\mathrm{S} 100 \mathrm{~B}$ has been reported to regulate $\mathrm{A} \beta$ biogenesis, amyloid precursor protein expression/processing and tau hyperphosphorylation [26-28]. In turn, the A $\beta$ peptide increases S100B levels [29] resulting in a positive feedback loop. Thus, S100B may be a key contributor to a detrimental "cytokine cycle" that drives the progression of $\mathrm{AD}[2,3,8,16,30]$.

In vivo studies in genetically modified mouse models have yielded conflicting results regarding the contribution of increased S100B expression to AD pathology. Transgenic TghuS100B mice express 4-5 fold more S100B protein [31] and exhibit increased hippocampal gliosis with no change in plaque load upon hippocampal $\mathrm{A} \beta$ infusion when compared to non-transgenic controls [32]. However, TghuS100B/Tg2576 mice exhibit increased plaque load/gliosis in the hippocampus as well as the cortex when compared to $\mathrm{Tg} 2576$ mice [26]. The mechanism(s) responsible for the differential effects of increased S100B expression on hippocampal pathology in the two AD models have not been elucidated. Pharmacological inhibition and genetic ablation have also produced contradictory results. Treatment of Tg2576 mice with arundic acid, an inhibitor of S100B expression (40-45\% decrease), reduces plaque load/gliosis in the hippocampus and cortex [33]. Surprisingly, S100B ablation has no effect on hippocampal plaque load, gliosis or dystrophic neurons in an $A \beta$ infusion model [32]. Thus, the ability of S100B inhibitors to prevent/reverse AD histopathology is not completely understood.

While specific inhibitors that block the interaction of S100B with its target proteins are under development, currently available compounds do not cross the bloodbrain barrier and cannot be used to inhibit CNS S100B [34]. Therefore, this study uses an in vivo genetic approach which recapitulates the entire spectrum of S100 function (detrimental, beneficial, intracellular, and extracellular) to ascertain the net effect of S100B ablation on AD histopathology in the PSAPP AD mouse line. Although no AD mouse model exhibits all aspects of the human disease, the PSAPP double transgenic $\left(\mathrm{APP}_{\mathrm{K} 670 \mathrm{NM} 671 \mathrm{~L}} / \mathrm{PS}-1_{\mathrm{M} 146 \mathrm{~L}}\right)$ line has a rapid disease onset and mimics many facets of the human disease including plaque deposition, dystrophic neurites, glial activation, and memory deficits [35-38]. PSAPP/S100B knockout mice exhibited a regionally selective decrease in cortical but not hippocampal plaque load. Reductions in plaque load were accompanied by decreases in plaque number, GFAP-positive astrocytes, Iba1-positive microglia and phospho-tau positive neurons. Finally, S100B immunoreactivity in cortex and hippocampus of PSAPP mice was plaque associated and co-localized with astrocytes/microglia. These results suggest that secreted and intracellular forms of S100B contribute to AD pathology and that pharmacological strategies which selectively block S100B action in the CNS may be effective in treating AD.

\section{Methods \\ PSAPP X S100B Knockout Mice}

The PSAPP double transgenic line was generated by crossing the Tg2576 line ("Swedish" APP ${ }_{\text {K670N/M671L }}$ mutation) with the 6.2 line (PS-1 $1_{\mathrm{M} 146 \mathrm{~L}}$ ) [35-38]. The $\mathrm{S}_{100 \mathrm{~B}^{-/-}}$line has been described previously [39]. The $\mathrm{PSAPP} / \mathrm{S} 100 \mathrm{~B}^{-/-}$line was generated by crossing PSAPP double transgenic males with $\mathrm{S}_{100 \mathrm{~B}^{-1-}}$ females and subsequent interbreeding of the PSAPP/S100B ${ }^{+/-}$heterozygous offspring (PSAPP $/ \mathrm{S} 100 \mathrm{~B}^{+/-} \mathrm{X} \mathrm{PSAPP} / \mathrm{S} 100 \mathrm{~B}^{+/}$). To control for changes in genetic background, all experiments used PSAPP $/ \mathrm{S}_{100 \mathrm{~B}^{+/+}}$and PSAPP $/ \mathrm{S} 100 \mathrm{~B}^{-/-}$littermates. Procedures involving animals were approved by the Texas A \& M University Institutional Animal Care and Use Committee and comply with the NIH Guide for the Care and Use of Laboratory Animals.

For genotyping, amplification of a 500 bp product using PCR primers for the mouse $\beta$-casein gene (forward primer 5' GAT GTG CTC CAG GCT AAA GTT 3' and reverse primer 5' AGA AAC GGA ATG TTG TGG AGT 3') was used to assess genomic DNA quality. The PS-1 and APP transgenes were detected as 
previously described [36]. Amplification of $250 \mathrm{bp}$ band (forward primer 5' GCA AAG AAC AGG GTA GAA AAC ATG AAA AAC G 3'; reverse primer 5' GCC ATT CAA ACT AAT ATC CAG AAG CAA CCC 3') was used to detect the wild-type S100B allele. PCR programs contained a 5 minute denaturation step at $95^{\circ} \mathrm{C}$; followed by thirty cycles consisting 1 minute at $94^{\circ} \mathrm{C}, 2$ minutes at $60^{\circ} \mathrm{C}$, and 3 minutes at $72^{\circ} \mathrm{C}$; as well as a final 7 minute extension step at $72^{\circ} \mathrm{C}$.

\section{Sample Acquisition/Processing}

Brains were removed from anesthetized animals, rinsed in phosphate buffered saline (PBS) and fixed in 4\% (wt/ vol) paraformaldehyde in PBS for 30 minutes. Sagittal slices, $2 \mathrm{~mm}$ in thickness, were prepared using an acrylic brain matrix (Ted Pella, Redding CA) and post-fixed for an additional 30 minutes. Slices were then permeabilized in $2 \mathrm{mM} \mathrm{MgCl}_{2}, 0.01 \%$ (wt/vol) sodium deoxycholate, $0.02 \%$ (vol/vol) Nonidet P-40 in $100 \mathrm{mM}$ sodium phosphate buffer $\mathrm{pH} 7.5$ for 36-48 hours. After post-fixation in $10 \%$ buffered formalin for 16 hours, tissues were embedded in paraffin and 5 micron sagittal sections were mounted on glass slides for subsequent staining. This processing procedure, originally developed for visualization of $\beta$-galactosidase reporter gene activity in transgenic mouse tissues, provides optimum S100B antibody specificity/sensitivity without compromising the detection of other antigens.

\section{Immunohistochemical and Congo red staining}

To minimize variability, sections from experimental and control groups were processed simultaneously. Consecutive slides (2/animal) each containing sections at Allen Brain Atlas Sagittal Levels 8 and 17 were depariffinized and rehydrated to distilled water. For Congo red staining, slides were incubated in $0.02 \mathrm{M} \mathrm{NaOH}$ in $80 \%$ ethanol saturated with $\mathrm{NaCl}$ for 20 minutes followed by a 30 minute incubation in $0.2 \%$ (wt/vol) Congo Red (Cat. 150711, MP Biomedicals, LLC, Solon, OH) in $0.02 \mathrm{M}$ $\mathrm{NaOH}$ in $80 \%$ ethanol saturated with $\mathrm{NaCl}$, dehydration and mounting. Immunostaining was performed on a DAKO autostainer (Dako, Carpinteria, CA) using a biotin-free polymer detection kit $(\mathrm{MACH} 2$, Biocare Medical, Walnut Creek, CA) and conditions recommended by the primary antibody manufacturer. Primary antibodies for immunohistochemistry included a mouse monoclonal S100B antibody (1-1000 dilution of Z0311 Dako); rabbit polyclonal GFAP antibody (1-1000 dilution of Z0334, Dako); mouse monoclonal Iba1antibody (1-300 dilution of SC-32725, Santa Cruz Biotechnology, Santa Cruz, CA); and mouse monoclonal Ser202/Thr205 phosphorylated tau antibody (1-20 dilution of MN1020, Pierce Chemical Co., Rockford, IL). For immunofluorescence microscopy, the anti-Iba1 antibody was diluted 1-10, the anti-GFAP antibody 1-100, and the anti-S100B antibody 1-50 (612377 from BD Transduction Laboratories, San Jose, CA). Secondary antibodies included an Alexa Fluor 546 donkey anti-rabbit (1-200 dilution of A10040, Molecular Probes, Carlsbad, CA); Alexa Fluor 488 rabbit antimouse (1-200 dilution of A11059, Molecular Probes); and Alexa Fluor 546 donkey anti-mouse (1-200 dilution of A10036, Molecular Probes).

For quantification, digital images were captured at $10 \times$ magnification on an Olympus IX70 Imaging System using a single exposure setting as follows: the entire hippocampus (2 images); the visual (1 image), somatosensory (1 image) and somatomotor (1 image) cortex as well as representative areas of the cerebellum and olfactory bulb. Images were converted to gray scale and the threshold intensity was set to the intensity observed in areas without tissue. Image J software (NIH Image, Bethesda, MD) was used to quantify positive pixels, plaque size, plaque number and total area. Plaque load and immunoreactivity were defined as the $\%$ area, i.e. the area of positive pixels/total pixels $\times 100$. The data were expressed as the mean \pm SEM $(n=8$ for PSAPP and $n$ $=6$ for PSAPP $\left./ \mathrm{S} 100 \mathrm{~B}^{-/-}\right)$. An independent samples $\mathrm{t}$-test (SPSS Inc., Chicago, IL) was used to determine the significance $(\mathrm{p}<0.05)$ of measured differences between the two genotypes. Pearson's Correlation Coefficient and scatter plots of the mean hippocampal and cortical GFAP/Iba1 burden versus plaque load for each animal were used to determine the relationship between plaque load and astrocytosis/microgliosis.

Images for colocalization experiments were obtained on a Zeiss 510 META NLO laser scanning microscope. The following settings were used for fluorophore detection: DAPI excitation G 365, Dichroic FT 395, BP 445/ 50; for Alexa 488, exciter BP470/20, Dichroic FT 493, Emission BP 505-530; and Alexa 568, Exciter BP560/40, Dichroic FT 585, Emission BP 630/75. Images were collected, corrected for background and bleedthrough (reference images) and colocalization (overlap coefficient) of GFAP/S100B and Iba1/S100B determined using the LSM software.

\section{Results}

\section{S100B ablation reduces cortical but not hippocampal} plaque load

To determine if S100B ablation altered amyloidogenesis, plaque load was quantified in PSAPP/S100B knockout and PSAPP mice. Congo red stained fibrillar plaques were observed in the hippocampus and cortex of 6 month old PSAPP/S100B ${ }^{-/}$and PSAPP mice (Figure 1A). In fact, congophilic plaque load in the control PSAPP littermates was indistinguishable from previous reports [35-38]. Furthermore, hippocampal plaque load in the two genotypes was indistinguishable: 


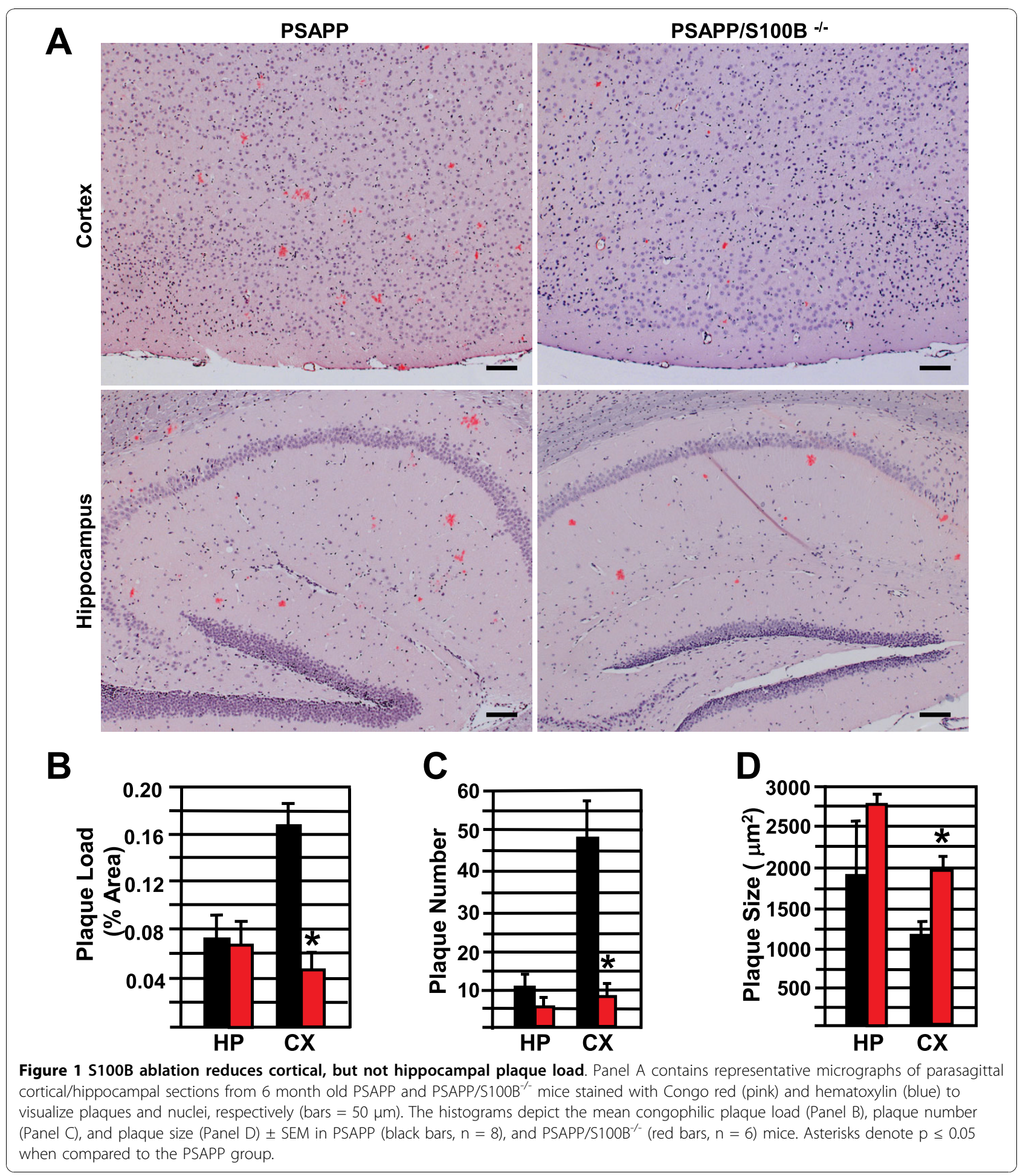

$0.070 \pm 0.020$ and $0.075 \pm 0.022$ percent area in the $\mathrm{PSAPP} / \mathrm{S}_{100 \mathrm{~B}^{-/-}}$and PSAPP controls, respectively (Figure $1 \mathrm{~B})$. Hippocampal plaque size and number were also similar in the two genotypes (Figure 1C and 1D). In contrast, there was a 3 -fold reduction in cortical plaque load in $\mathrm{PSAPP} / \mathrm{S} 100 \mathrm{~B}^{-/-}$mice $(0.050 \pm 0.016$ percent area) when compared to PSAPP mice $(0.168 \pm 0.016$ percent area) (Figure 1B). This decrease in cortical plaque load was accompanied by an 5 -fold reduction in plaque number $(47.78 \pm 9.42$ vs $8.78 \pm 2.07)$ and a slight increase in plaque size $\left(1162 \pm 141\right.$ vs $\left.1955 \pm 196 \mu^{2}\right)$ (Figure 1C and 1D). In summary, this is the first 
demonstration that $\mathrm{S} 100 \mathrm{~B}$ ablation selectively reduces cortical plaque load.

\section{S100B ablation decreases cortical, but not hippocampal, gliosis}

S100B's deleterious effects in the central nervous system have been attributed to reactive gliosis (astrocytosis and microgliosis) $[23,26,32,33]$. The microglial marker Iba1 and astrocytic marker GFAP were used to determine if S100B ablation in PSAPP mice also reduced gliosis. Plaque-associated Ibal staining of small cell bodies and long processes was observed in the cortex and hippocampus of PSAPP and PSAPP/S100B ${ }^{-1-}$ mice (Figure $2 \mathrm{~A}$ and $2 \mathrm{~B})$. This staining pattern was similar to previous reports for AD mouse models (Tg2576) [26,33]. Hippocampal Iba1 burden in the two genotypes was similar $(0.51 \pm 0.12$ vs. $0.51 \pm 0.10$ percent area) (Figure $2 \mathrm{C})$. However, cortical Iba1 burden was 4 -fold less $(0.45 \pm$ 0.09 vs $1.69 \pm 0.49$ percent area) in PSAPP/S100B ${ }^{-/-}$ mice when compared to PSAPP control mice (Figure $2 \mathrm{C})$. In both genotypes, the Iba1 burden was similar in non-plaque containing regions such as the cerebellum (Figure 2A) and olfactory bulb (data not shown). Furthermore, there was a direct correlation between Iba1 burden and plaque load (Pearson's Correlation Coefficient 0.654, $\mathrm{p}<0.0005$ ) (Figure 2D). Hippocam$\mathrm{pal} /$ cortical plaque-associated GFAP positive astrocytes were also observed in both genotypes (Figure $3 \mathrm{~A}$ and $3 \mathrm{~B}$ ) and the staining pattern (somata and processes) was indistinguishable from previous reports for $A D$ mouse models [26,33]. Hippocampal GFAP burden was similar ( $4.53 \pm 0.67$ vs. $5.52 \pm 1.35$ percent area) while cortical GFAP burden was 2 -fold less $(3.56 \pm 0.92$ vs. $7.26 \pm$ 1.40 percent area) in PSAPP/S100B ${ }^{-/-}$mice when compared to PSAPP control mice (Figure 3C). In addition, GFAP burden in non-plaque containing regions such as the cerebellum (Figure 3A) and olfactory bulb (data not shown) was similar in the two genotypes. Like Iba1, there was a direct correlation between GFAP burden and plaque load (Pearson's Correlation Coefficient 0.722 $\mathrm{p}<0.0005)$ (Figure 3D). Collectively, these findings demonstrate that S100B ablation results in regionally selective decreases in microgliosis and astrocytosis that directly correlate with plaque load.

\section{Effects of S100B ablation on dystrophic neurons}

Although the correlation between plaque load and cognitive function remains controversial, decreases in plaque load are commonly accompanied by reductions in dystrophic neurons/neurites and improvements in cognitive function. In fact, changes in phospho-tau levels/ staining are used to detect dystrophic neurons in PSAPP and Tg2576 mice despite the fact that these models do not develop tangles [40-42]. Therefore, the AT8 phospho-tau antibody, which detects phospho-Ser202/ Thr205, was used to ascertain the effect of S100B ablation on dystrophic neurons. The hippocampal and cortical phospho-tau staining patterns in both genotypes was indistinguishable from previous reports: punctate plaque-associated staining (Figure 4). These results demonstrate that $\mathrm{S} 100 \mathrm{~B}$ ablation does not prevent the development of plaque-associated dystrophic neurons. However, as predicted by the plaque load results, $\mathrm{PSAPP} / \mathrm{S} 100 \mathrm{~B}^{-1-}$ mice exhibited fewer cortical but similar numbers of hippocampal phospho-tau foci/plaques when compared to PSAPP mice (Figure 4).

\section{S100B colocalizes with hippocampal as well as cortical astrocytes, microglia, and plaques}

In human autopsy specimens and the Tg2576 mouse model, S100B staining is associated with astrocytes and plaques $[22,23,26]$. In addition, in human $A D$ the highest levels of S100B are observed in the most severely affected regions [23]. Therefore, S100B immunohistochemistry was used to determine if differences in S100B distribution were responsible for the regionally selective effects of S100B ablation on histopathology in PSAPP mice. In nontransgenic mice, intense staining of astrocytic cell bodies/processes and diffuse cytoplasmic/extracellular S100B staining was observed in the hippocampus and cortex (Figure 5). PSAPP mice exhibited a similar staining pattern as well as punctate plaque-associated staining (Figure 5). The increased staining intensity in PSAPP mice when compared to nontransgenic mice is consistent with previous reports of increased S100B expression in $\mathrm{AD}$ [1-3]. Sections from PSAPP/S100B ${ }^{-/-}$mice exhibited no detectable staining (Figure 5) indicating that plaqueassociated and diffuse cytoplasmic/extracellular staining were not attributable to non-specific antibody binding and/or high background. The S100B staining pattern observed in PSAPP mice was similar to staining patterns observed in the Tg2576 AD mouse model [33] and human autopsy specimens [43]. The cellular distribution of S100B in PSAPP mice was confirmed by double immunofluorescence staining with astrocytic (GFAP, overlap coefficient $0.8083 \pm 0.0149$ ) and microglial (Iba1, overlap coefficient $0.8476 \pm 0.0356$ ) markers (Figure 6). Collectively, these findings suggest that both intracellular and extracellular forms of S100B may contribute to AD histopathology. In conclusion, the regionally selective effects of S100B ablation on histopathology are most likely attributable to regional differences in the cellular processes that are regulated by S100B and not differences in S100B expression/distribution.

\section{Discussion}

This study definitively demonstrates that S100B ablation/inhibition reduces AD pathology. PSAPP/S100B 


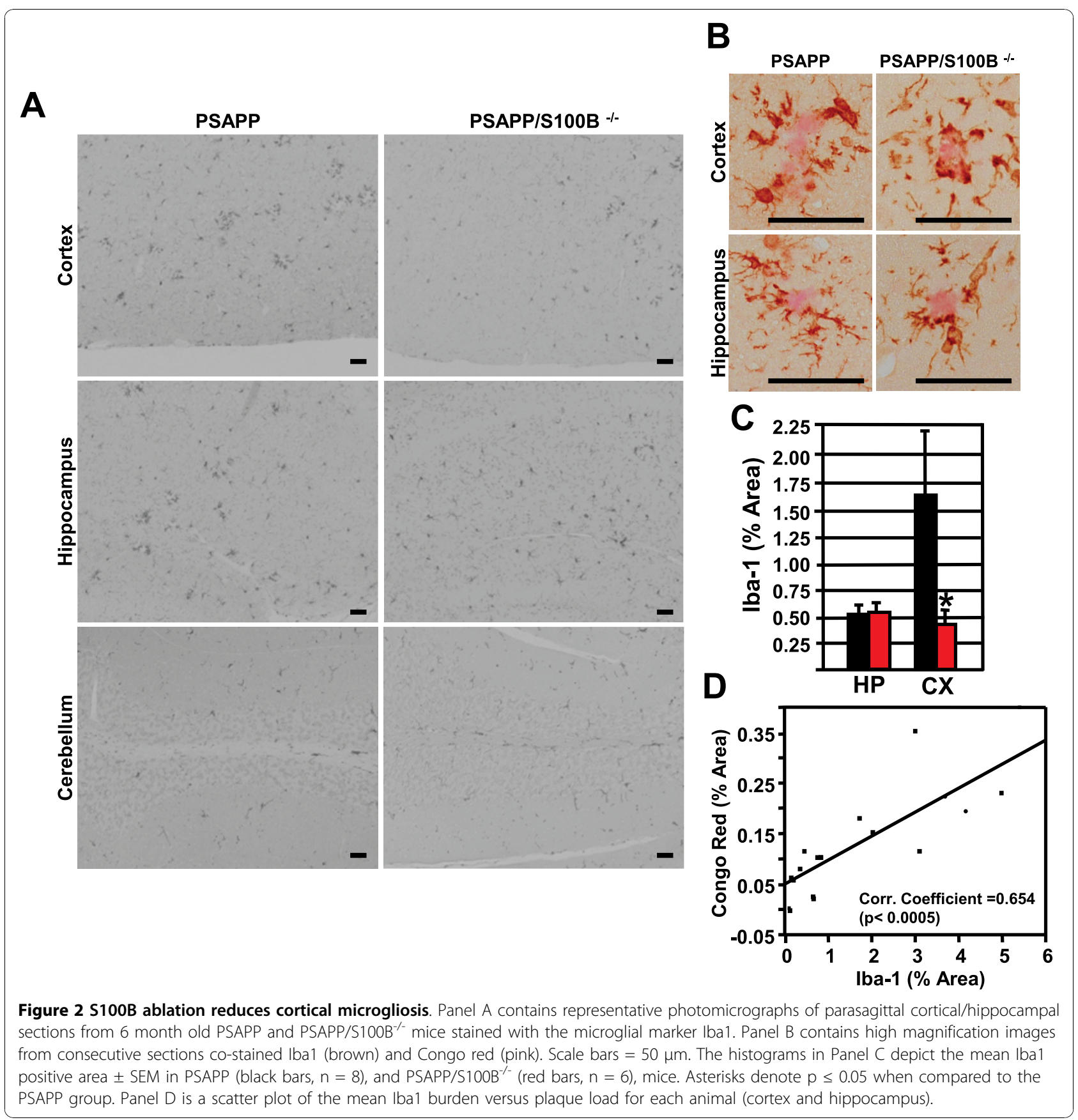

knockout mice exhibited a regionally selective decrease in cortical but not hippocampal plaque load that was accompanied by reductions in astrocytosis, microgliosis and dystrophic neurons. These regionally selective effects were not attributable to variations in the S100B distribution; cortical and hippocampal S100B staining patterns were indistinguishable in PSAPP mice. Finally, in PSAPP mice S100B immunoreactivity was associated with plaques and colocalized with astrocytes as well as microglia suggesting that both intracellular and extracellular S100B contribute to AD histopathology. Interestingly, other studies have reported regionally selectively effects of S100B ablation on $\mathrm{Ca}^{2+}$ handling, synaptic plasticity, kainate-induced gamma amplitudes and BDNF (brain-derived neurotrophic factor) levels [44-47]. Ascertaining the molecular mechanisms responsible for S100B's selective effects on AD histopathology and other processes may provide new insights regarding the events that contribute to the non-uniform progression of AD [48-50]. 


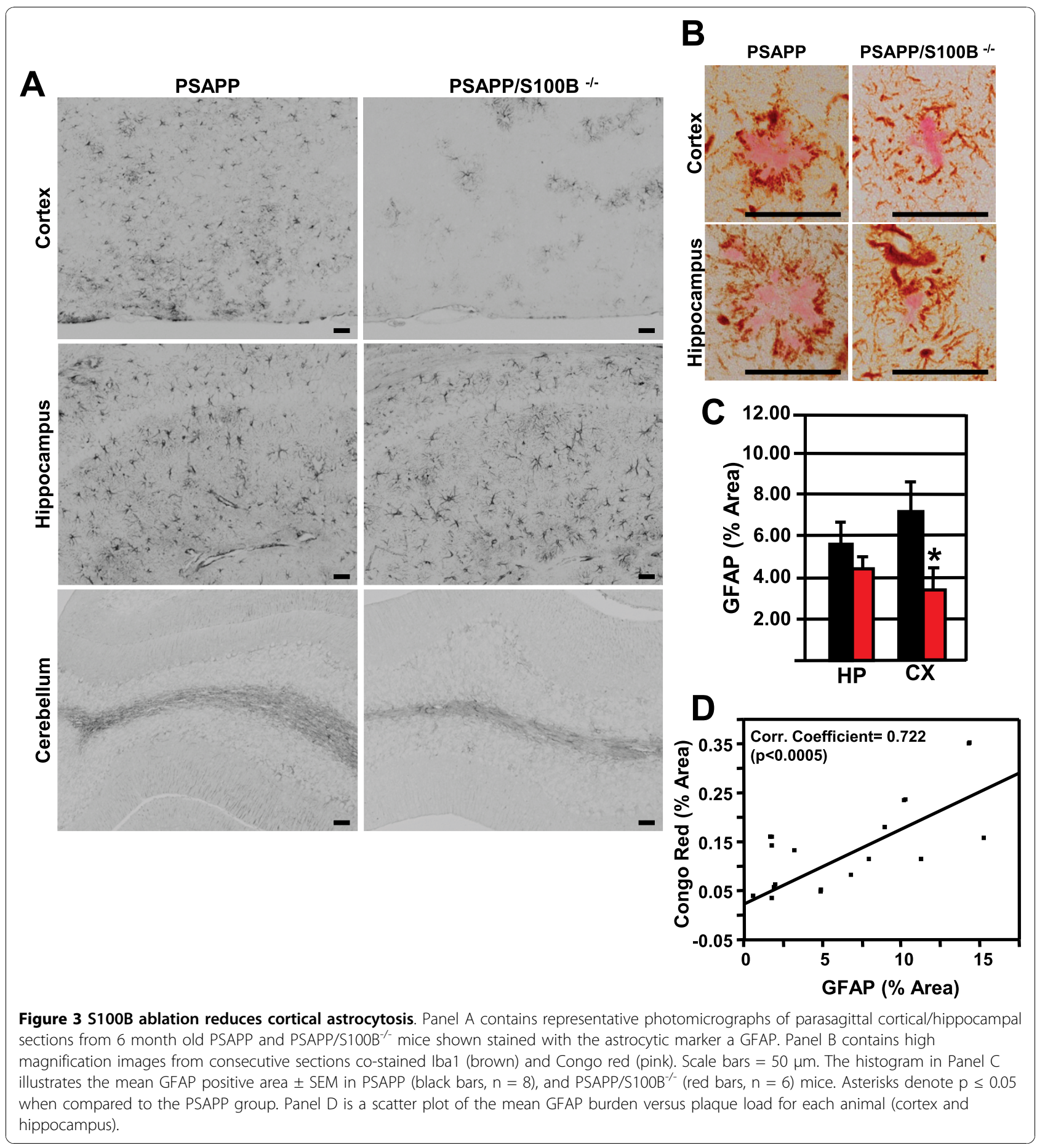

These findings clarify inconsistencies in the literature regarding S100B's contribution to AD histopathology. Genetic ablation (this study), pharmacological inhibition [33] and genetic overexpression [26] approaches consistently indicate that decreases in $\mathrm{S100B}$ reduce AD histopathology in the cortex. The larger effects observed with genetic ablation may be due to maximal inhibition; pharmacological inhibition reduces S100B levels by 40 -
$50 \%$ and genetic overexpression increases S100B levels by $30 \%[26,33]$. In all $\mathrm{S} 100 \mathrm{~B}^{-1-}$ mice hippocampal plaque load remains unchanged regardless of the mechanism used to induce plaque deposition, i.e. A $\beta$ infusion [32] or overexpression of mutant proteins (APP and PS-1) in transgenic mice (this study). However, pharmacological inhibition of S100B synthesis with arundic acid in mice that overexpress mutant APP (TG2576 line) reduces 


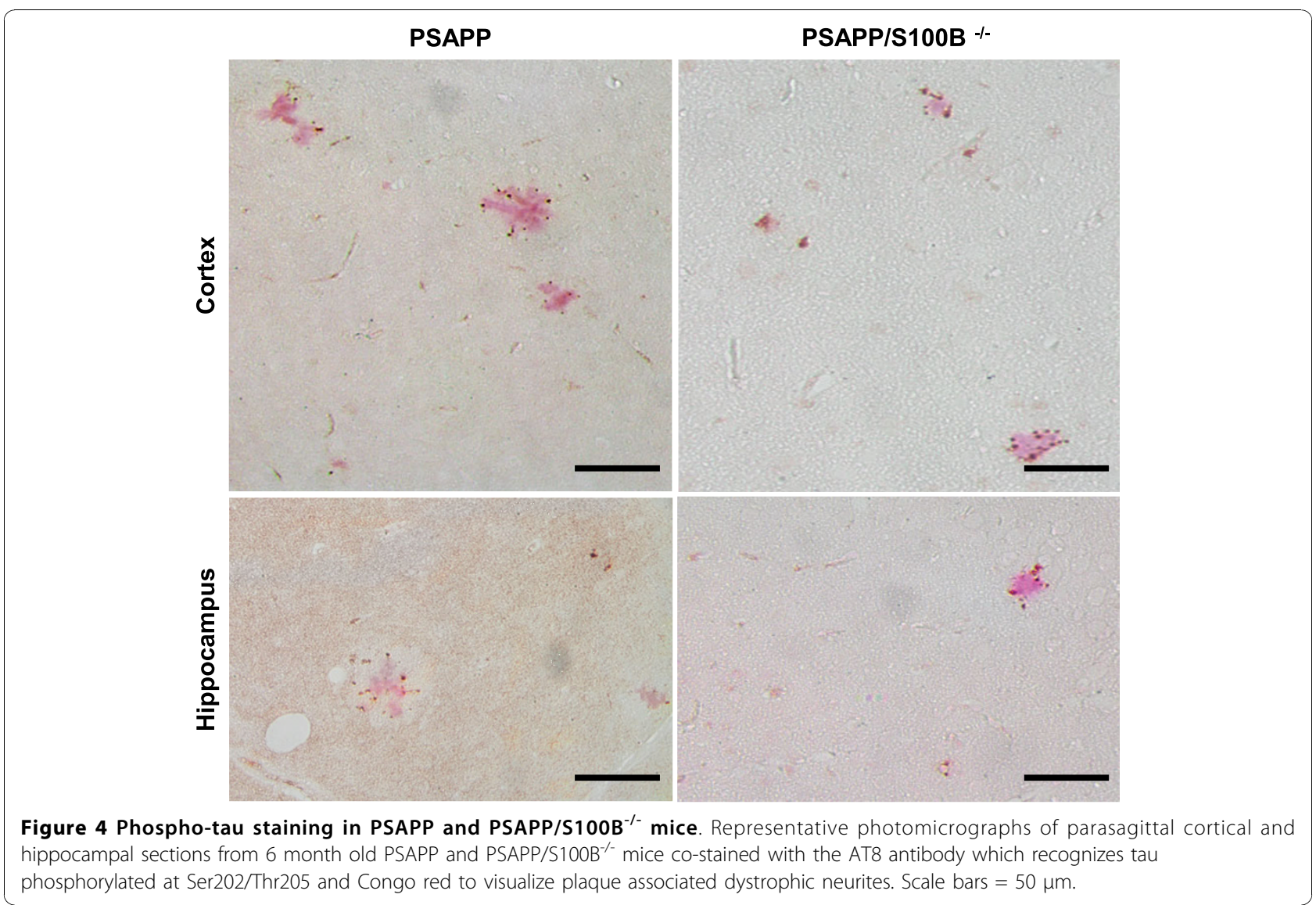

hippocampal plaque load/gliosis [33] and overexpression of S100B in the same model increases hippocampal plaque load/gliosis [26]. These differential effects may be due to alternative mechanisms of action for arundic acid [51], upregulation of compensatory mechanisms in knockout models, gain of function in overexpression models, differences in the AD mouse models and/or variations the ages of the animals.

A consistent finding in this and previous studies is a direct correlation between changes in plaque load and gliosis/inflammation in response to alterations in S100B expression. It is unclear, however, whether changes in plaque load are the cause or the result of changes in gliosis. Furthermore, it is unclear how these histopathological changes impact cognitive function. Microglia are an essential component of the inflammatory response and exist in many forms $[52,53]$. They beneficially phagocytose plaques and suppress inflammation as well as detrimentally promote inflammation and neuronal cell death [54-56]. Detailed analyses of microglial/glial phenotypes in PSAPP $/ \mathrm{S} 100 \mathrm{~B}^{-/-}$mice will be instrumental in identifying S100B-regulated events that contribute to $A D$ pathology and in discerning the relationship between plaques and inflammation. Behavioral data are not available for any of the S100B/AD mouse models.
Strengthened synaptic plasticity and enhanced spatial memory in $\mathrm{S}_{100 \mathrm{~B}^{-1-}}$ mice [44] suggest that PSAPP/ $\mathrm{S}_{100 \mathrm{~B}^{-/-}}$mice will exhibit improved cognitive function. This hypothesis is supported by the inverse correlation of serum/CSF S100B levels and direct correlation of the rs2300403 SNP in the S100B gene with low cognitive performance, dementia and $\mathrm{AD}[24,25]$. Experiments are underway to determine if pharmacological inhibition of S100B expression and/or interaction of S100B with its target proteins will improve cognitive function in $\mathrm{AD}$ and/or other neurological disorders.

S100B's plaque association and co-localization with cells (microglia/astrocytes) in this and previous studies $[22,23,33]$ suggest that both intracellular and extracellular S100B contribute to AD pathology. Inhibition of intracellular S100B would be predicted to reduce $A \beta$ induced spontaneous calcium transients [29], decrease inflammatory cytokine release $[2,3,30]$ and prevent $A \beta$ induced increases in S100B levels [10]. Inhibition of extracellular S100B would be predicted to alter $\mathrm{Ca}^{2+}$ handling, synaptic plasticity long-term potentiation, neuronal apoptosis and/or BDNF levels [39,43-47,57,58]. Decreased extracellular S100B-RAGE/scavenger receptor signaling in glia, neurons and/or endothelial cells [7,9,59-64] could also impact APP synthesis, APP 


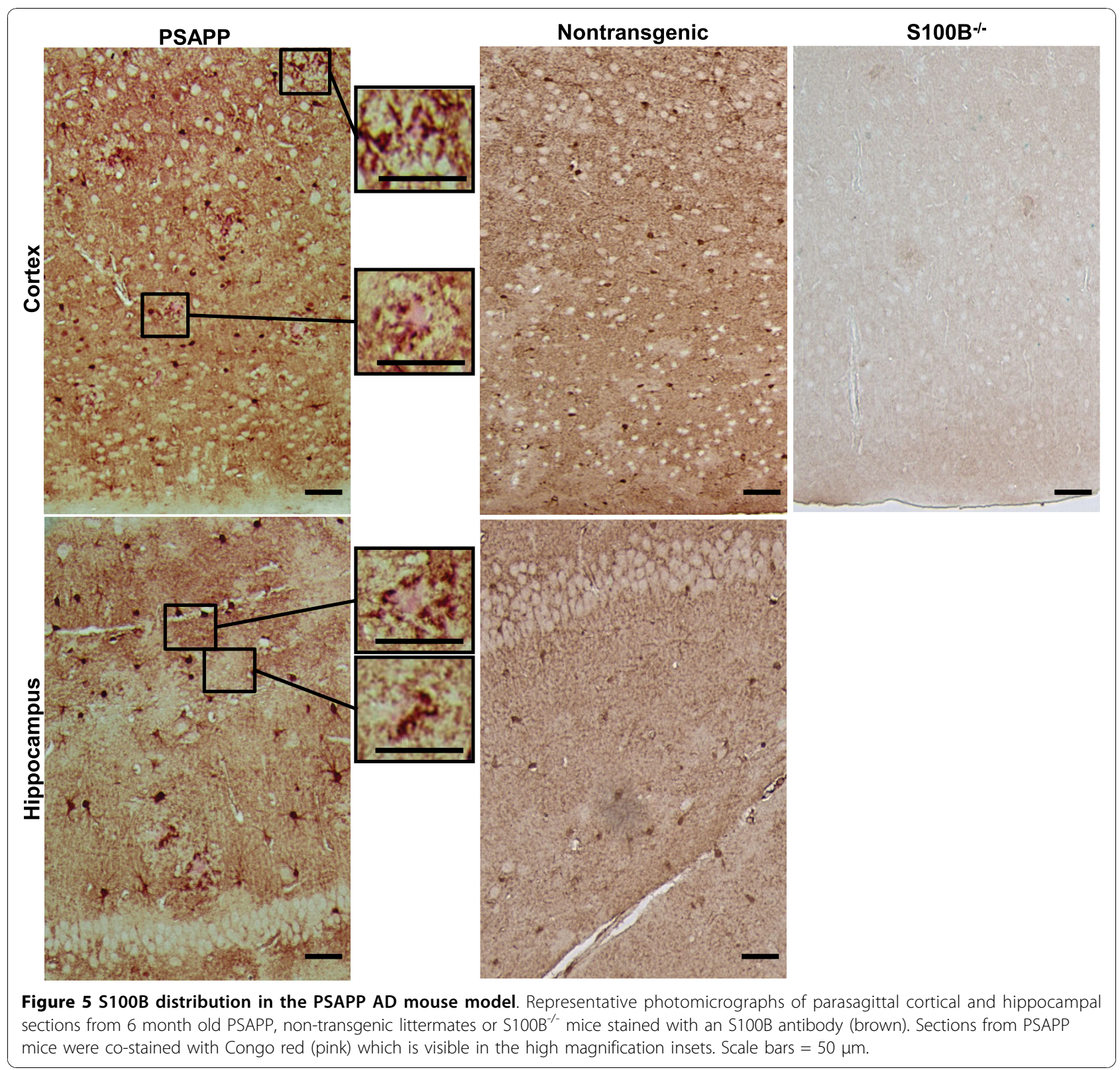

processing and/or tau phosphorylation (GSK3 $\beta$, cdk5 and/or PKA pathways) [18-21]. In fact, intracellular/ extracellular S100B may link dysregulation of $\mathrm{Ca}^{2+}$ homeostasis with AD pathobiology and/or serve as a common upstream regulator of both tau phosphorylation/neurofibrillary tangles and $A \beta$ production/plaque deposition [18-21]. While astrocytes, microglia and oligodendrocytes are the most logical source of S100B, peripheral tissues such as adipose cannot be excluded [65-67]. Defining the source of and mechanisms of release/secretion for S100B will be important steps in delineating the S100B-regulated processes that contribute to AD histopathology.

\section{Conclusions}

Collectively, these data definitively demonstrate that S100B ablation reduces plaque load, gliosis and dystrophic neurons in the cortex but not the hippocampus. If this reduction in histopathology can be demonstrated to positivity impact cognitive changes related to $\mathrm{AD}$, then additional impetus to the search for new therapeutic interventions targeted at S100B will be provided. The development of effective pharmacological strategies for modulating S100B function in patients will also require quantifying the contribution of extracellular versus intracellular forms, identifying the S100B-regulated target proteins/cellular processes, and ascertaining the contribution of the five other S100 


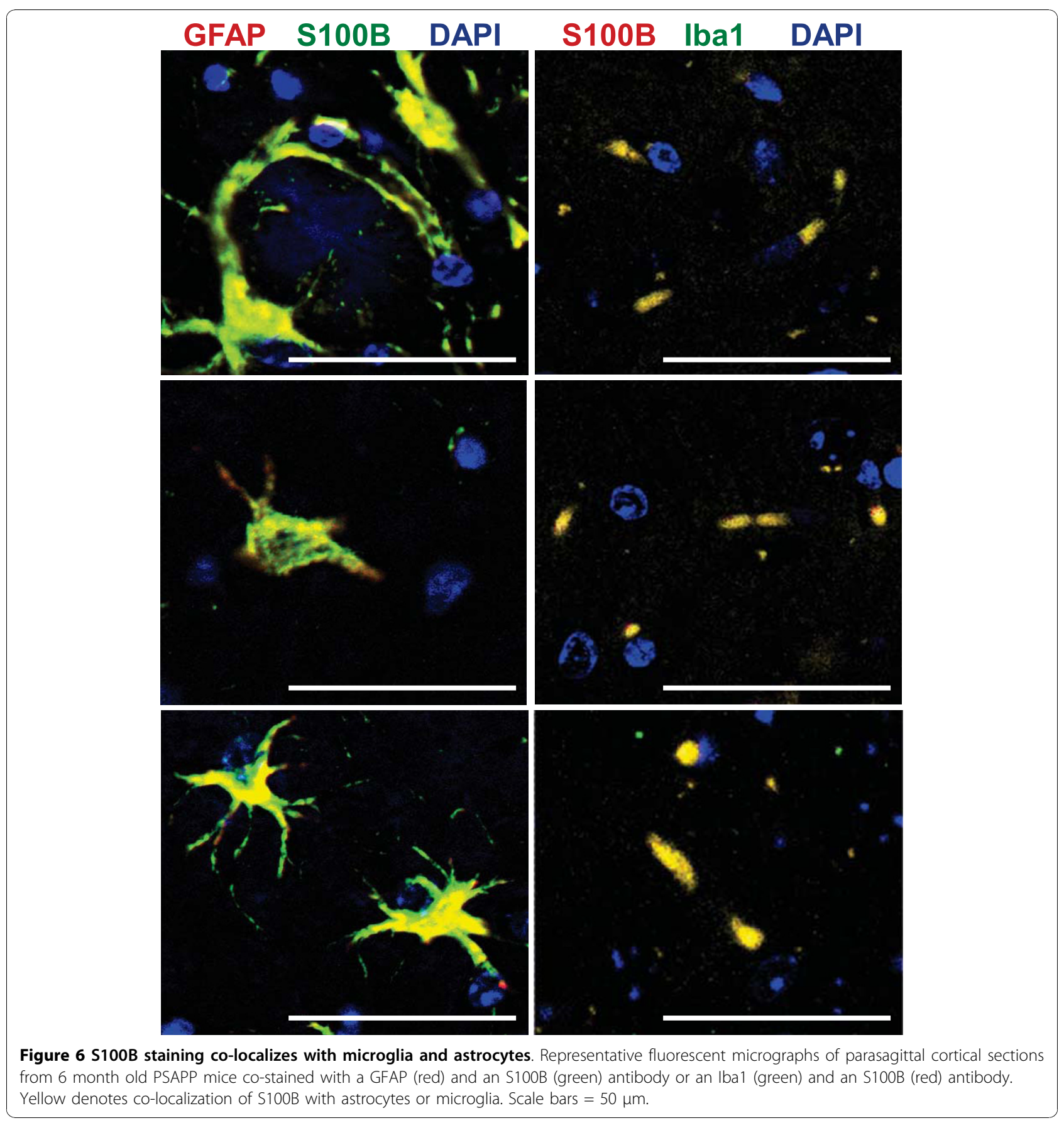

family members implicated in AD, S100A1, S100A6, S100A7, S100A9, and S100A12 [1,68-70]. Finally, the beneficial effects of S100B ablation/inhibition may extend to other neurological disorders that involve dysregulation of glial cell calcium homeostasis [71,72].

\section{Acknowledgements}

The authors would like to acknowledge Drs. Robert Burghardt and Rola Barhoumi Mouneimne as well as the Image Analysis Laboratory in the
College of Veterinary Medicine \& Biomedical Sciences for assistance with the co-localization studies and Dr. Gregg Wells for critical reading of the manuscript. We also thank Dr. Andy Ambrus and Ms. Lin Bustamante for technical assistance with immunohistochemistry and tissue processing, respectively. These studies were supported by Texas A \& M University startup funds.

\section{Author details}

'Department of Veterinary Pathobiology, Texas A\&M University, College Station, TX, USA. ${ }^{2}$ Psychiatry and Behavioral Science, Texas A \& M Health Science Center, College of Medicine, Temple, TX, USA. ${ }^{3}$ Central Texas Veterans Health Care System Neuropsychiatry Research Program, Temple, TX, 
USA. ${ }^{4}$ Banting \& Best Department of Medical Research, University of Toronto, Ontario, Canada.

\section{Authors' contributions}

$\mathrm{LH}$ and $\mathrm{KY}$ provided the PSAPP mouse line. AM provided the S100B knockout mouse line. DZ and LH conceived the study and developed the PSAPP/S100B knockout mouse line. ER performed the experiments and participated in the writing of the manuscript as partial fulfillment of the requirements for the $\mathrm{PhD}$ degree. $\mathrm{DZ}$ supervised the data collection/analyses and drafted the manuscript. All authors read and approved the final manuscript.

\section{Competing interests}

The authors declare that they have no competing interests.

Received: 18 June 2010 Accepted: 16 November 2010 Published: 16 November 2010

\section{References}

1. Zimmer DB, Chaplin J, Baldwin A, Rast M: S100-mediated signal transduction in the nervous system and neurological diseases. Cell $\mathrm{Mol}$ Biol 2005, 51:201-214.

2. Mrak RE, Griffin WS: Trisomy 21 and the brain. J Neuropathol Exp Neurol 2004, 27:512-518.

3. Van Eldik LJ, Wainwright MS: The Janus face of glial-derived S100B: beneficial and detrimental functions in the brain. Restor Neurol Neurosci 2003, 21:97-108.

4. Moore BW: A soluble protein characteristic of the nervous system. Biochem Biophys Res Comm 1965, 19:739-744.

5. Zimmer DB, Sadosky PW, Weber D: Molecular mechanisms of S100-target protein interactions. Microscopy Res Technique 2003, 60:552-559.

6. Zimmer DB, Weber DJ: The calcium dependent interaction of S100B with its protein targets. Cardiovasc Psychiatry Neurol 2010

7. Hoffman MA, Srury S, Fu C, Qu W, Taguchi A, Lu Y, Avila C, Kambham N, Bierhaus A, Nawroth P, Meurath MF, Slattery T, Beach D, McClary J, Nagashima M, Morser J, Stern D, Schmidt AM: RAGE mediates a novel proinflammatory axis: a central cell surface receptor for S100/calgranulin polypeptides. Cell 1999, 97:889-910.

8. Leclerc E, Sturchler E, Vetter SW: The S100B/RAGE axis in alzheimer's disease. Cardiovasc Psychiatry Neurol 2010

9. Hu J, Castets F, Buevara JL, Van Eldik LJ: $S 100 \beta$ stimulates inducible nitric oxide synthase activity and mRNA levels in rat cortical astrocytes. J Biol Chem 1996, 271:2543-2547.

10. Pena LA, Brecher CW, Marshak DR: $\beta$-amyloid regulates gene expression of glial trophic substance $S 100 \beta$ in $C 6$ glioma and primary astrocyte cultures. Mol Brain Res 1995, 34:118-126.

11. Pinto SS, Gottfried C, Mendez A, Goncalves D, Karl J, Goncalves CA, Wofchuk S, Rodnight R: Immunocontent and secretion of S100B in astrocyte cultures from different brain regions in relation to morphology. FEBS Lett 2002, 486:, 203-207.

12. Whitaker-Azmitia PM, Murphy R, Azmitia EC: Stimulation of astroglial 5HT1A receptors releases the serotonergic growth factor, protein S-100, and alters astroglial morphology. Brain Res 1990, 528:155-158.

13. Tramontina F, Tramontina AC, Souza DF, Leite MC, Gottfried C, Souza DO, Wofchuk ST, Goncalves CA: Glutamate uptake is stimulated by extracellular S100B in hippocampal astrocytes. Cell Mol Neurobiol 2006, 26:81-86.

14. Quincozes-Santos A, Rosa RB, Leipnitz G, de Souza DF, Seminotti B, Wajner M, Goncalves CA: Induction of S100B secretion in C6 astroglial cells by the major metabolites accumulating in glutaric acidemia type 1 . Metab Brain Dis 2010, 25:191-198.

15. Nogueira MI, Abbas SY, Campos LGM, Allemandi W, Lawson P, Takada SH, Azimitia EC: S100B protein expression: gender and age-related daily changes. Neurochem Res 2009, 34:1355-1362.

16. Sorci G, Bianchi R, Riuzzi F, Tubaro C, Arcuri C, Giambanco I, Donato R: S100B protein, a damage-associated molecular pattern protein in the brain and heart, and beyond. Cardiovasc Psychiatry Neurol 2010.

17. Mori T, Asano T, Town T: Targeting S100B in cerebral ischemia and in alzheimer's disease. Cardiovasc Psychiatry Neurol 2010.

18. Demuro A, Parker I, Stutzmann GE: Calcium signaling and amyloid toxicity in Alzheimer disease. J Biol Chem 2010, 285:12463-12468.
19. Supnet C, Bezprozvanny I: The dysregulation of intracellular calcium in Alzheimer disease. Cell Calcium 2010, 4:183-189.

20. Querfurth HW, LaFerla FM: Alzheimer's disease. New England J Med 2010, 362(3):29-344.

21. Small SA, Duff $K$ : Linking $A \beta$ and tau in late-onset Alzheimer's disease: a dual pathway hypothesis. Neuron 2008, 60:534-5542.

22. Marshak DR, Pesce SA, Stanley LC, Griffin WS: Increased S100 beta neurotrophic activity in Alzheimer's disease temporal lobe. Neurobiol Aging 1992, 13:1-7.

23. Van Eldik LJ, Griffin WST: S100ß expression in Alzheimer's disease: relation to neuropathology in brain regions. Biochim Biophys Acta 1994, 1223:398-403.

24. Chaves ML, Camozzato AL, Ferreira ED, Piazenski I, Kochhann R, Dall'Igna O, Mazzini GS, Souza DO, Portela LV: Serum levels of S100B and NSE proteins in Alzheimer's disease patients. J Neuroinflamm 2010, 7:6.

25. Lambert J-C, Ferreira S, Gussekloo J, Christiansen L, Brysbaert G, Slagboom E, Cottel D, Petit T, Hauw J-J, DeKosky ST, Richard F, Berr C, Lendon C, Kamboh Ml, Mann D, Christensen K, Westendorp R, Amouyel P: Evidence for the association of the $\mathrm{S100B}$ gene with low cognitive performance and dementia in the elderly. Mol Psychiatry 2007, 12:870-880.

26. Mori T, Koyama N, Arendash GW, Horikoshi-Sakuraba Y, Tan J, Towne T: Overexpression of human $\mathrm{S100B}$ exacerbates cerebral amyloidosis and gliosis in the TG2576 mouse model of Alzheimer's disease. GLIA 2010, 58:300-314.

27. Anderson PBJ, Watts HR, Jen $S$, Gentleman SJ, Moncaster JA, Walsh DT, Jen L-S: Differential effect of interleukin-1 $\beta$ and S100B on amyloid precursor protein in rat retinal neurons. Clin Opthamol 2009, 3:235-242.

28. Esposito G, Scuderi C, Lu J, Savani C, De Filippis D, luvone T, Steardo L, Sheen V, Steardo L: S100B induces tau protein hyperphosphorylation via Dickopff-1 up-regulation and disrupts the Wnt pathway in human neural stem cells. J Cell Mol Med 2008, 12:914-927.

29. Chow S-K, Yu D, MacDonald CL, Buibas M, Silva BA: Amyloid- $\beta$ directly induces spontaneous calcium transients, delayed intercellular calcium waves, and gliosis in rat cortical astrocytes. ASN Neuro 2010, 2, art: e00026.

30. Sen J, Belli A: S100B in neuropathologic states: the CRP of the brain? J Neurosci Res 2007, 85:1373-1380.

31. Friend WC, Clapoff $S$, Landry C, Belcker LE, O'Hanlon D, Allore RJ, Brown IR, Marks A, Roder J, Dunn RJ: Cell-specific expression of high levels of human $\mathrm{S} 100$ beta in transgenic mouse brain is dependent on gene dosage. J Neurosci 1992, 12:4337-4346.

32. Craft JM, Watterson DM, Marks A, Van Eldik LJ: Enhanced susceptibility of S-100B transgenic mice to neuroinflammation and neuronal dysfunction induced by intracerebroventricular infusion of human beta-amyloid. GLIA 2005, 51:209-216.

33. Mori T, Town T, Tan J, Yada N, Horikoshi Y, Yamamoto J, Shimoda T, Tateishi N, Asano T: Arundic acid ameliorates cerebral amyloidosis and gliosis in Alzheimer transgenic mice. J Pharmacol Exp Ther 2006, 318:571-578.

34. Markowitz J, MacKerell AD, Weber DJ: A search for inhibitors of S100B, a member of the $\mathrm{S} 100$ family of calcium-binding proteins. Mini Rev Med Chem 2007, 7:609-616.

35. Holcomb LA, Gordon MN, McGowan E, Yu X, Benkovic S, Jantzen P, Sright K, Saad I, Mueller R, Morgan D, Sanders S, Zehr C, O'Campo K, Hardy J, Prada CM, Eckman C, Younkin S, Hsiao K, Duff K: Accelerated Alzheimer-type phenotype in transgenic mice carrying both mutant amyloid precursor protein and presenilin 1 transgenes. Nat Med 1998, 4:97-100.

36. Holcomb LA, Gordon MN, Jantzen P, Hsiao K, Duff K, Morgan DG: Behavioral changes in transgenic mice expressing both amyloid precursor protein and presenilin-1 mutations: Lack of association with amyloid deposits. Behavior Genet 1999, 29:177-185.

37. Gordon MN, King DL, Diamond DM, Jantzen PT, Boyett KV, Hope $C E$, Hatcher JM, DiCarlo G, Gottschall WP, Morgan D, Arendash GW: Correlation between cognitive deficits and A $\beta$ deposits in transgenic APP+PS1 mice. Neurobiol Aging 2001, 22:377-385.

38. Gordon MN, Holcomb LA, Jantzen P, DiCarlo G, Connor K, Melachrino J, O'Callaghan J, Morgan D: Time course of the development of Alzheimerlike pathology in the doubly transgenic mPS1+mAPP mouse. Exp Neurol 2002, 173:183-195. 
39. Xiong Z, O'Hanlon D, Becker LE, Roder J, MacDonald JF, Marks A: Enhanced calcium transients in glial cells in neonatal cerebellar cultures derived from S100B null mice. J Exp Cell Res 2000, 257:281-289.

40. Hou Y, Zhu E, Rrapo J, Tian M, Takashi D, Commins E, He JSinger, Fernandez F, Tan J: HIV-1 Tat contributes to alzheimer's disease-like pathology in PSAPP mice. Int J Clin Exp Pathol 2009, 2:433-443.

41. Ricobaraza A, Cuadrado-Tejedor M, Perez-Mediavilla A, Frechilla D, Del Rio J, Garcia-Osta A: Phenylbutyrate ameliorates cognitive deficit and reduces tau pathology in an Alzheimer's disease mouse model. Neuropsychopharmacology 2009, 34:1721-32.

42. Tomiyama T, Matsuyama S, Iso H, Umeda T, Takuma H, Lhnishi K, Ishibashi K, Teraoka R, Sakama N, Yamashita T, Nishitsuji K, Ito K, Shimada H, Lambert MP, Klein WL, Mori H: A mouse model of amyloid $\beta$ oligomers: Their contribution to synaptic alteration, abnormal tau phosphorylation, glial activation, and neuronal loss in vivo. J Neurosci 2010, 30:4845-4856.

43. Sheng JG, Mrak RE, Rovnaghi CR, Kozlowska E, Van Eldik LJ, Griffin WST: Human brain S100b and S100b mRNA expression increases with age: pathogenic implications for Alzheimer's disease. Neurobiol Aging 1996, 17:359-363.

44. Nishiyama H, Knopfel T, Endo S, Itohara S: Glial S100B modulates longterm neuronal synaptic plasticity. Proc Natl Acad Sci, USA 2002, 99:4037-4042

45. Sakatini S, Seto-Ohshima A, Itohara S, Hirase H: Impact of S100B on local field potential patterns in anesthetized and kainic acid-induced seizure conditions in vivo. Eur J Neurosci 2007, 25:1144-1154.

46. Sakatani S, Seto-Ohshima A, Shinohara Y, Yamamoto Y, Yamamoto H, Itohara S, Hirase H: Neural-activity-dependent release of S100B from astrocytes enhances kainate-induced gamma oscillations in vivo. $J$ Neurosci 2008, 28:10928-10936.

47. Schulte-Herbruggen $\mathrm{O}$, Hortnagl $\mathrm{H}$, Ponath $\mathrm{G}$, Rothermundt $\mathrm{M}$, Hellweg R: Distinct regulation of brain-derived neurotrophic factor and noradrenaline in S100B knockout mice. Neurosci Letters 2008, 442:100-103.

48. Gomez-Isla T, Price JL, McKeel DW, Morris JC, Growdon JH, Hyman BT: Profound loss of layer II entorhinal cortex neurons occurs in very mild alzheimer's disease. J Neurosci 1996, 16:4491-4500.

49. Romito-Diiacomo RR, Menegay $\mathrm{H}$, Cicero SA, Herrup K: Effects of Alzheimer's disease on different cortical layers: the role of intrinsic differences in A $\beta$ susceptibility. J Neurosci 2007, 27:8496-8504.

50. Hyman BT, Van Hoesen GW, Damasio AR, Barnes DL: Alzheimer's disease: cell-specific pathology isolates the hippocampal formation. Science 1984, 225:1168-1170

51. Asano T, Mori T, Shimoda T, Shinagawa R, Satoh S, Yada N, Katsumata S, Matsuda S, Kagamiishi Y, Tateishi N: Arundic acid (ONO-2506) ameliorates delayed ischemic brain damage by preventing astrocytic overproduction of S100B. Curr Drug Targets CNS Neurol Disord 2005, 4:127-142.

52. Perry VH, Nicoll JAR, Holmes C: Microglia in neurodegenerative disease. Nat Rev Neurol 2010, 4:193-201.

53. Morgan D: Modulation of microglial activation state following passive immunization in amyloid depositing transgenic mice. Neurochem Int 2006, 49:190-194.

54. Heneka MT, Nadrigny F, Regen T, Martinez-Hernanadez A, DumitrescuOzimek L, Terwel D, Jardanhazi-Kurutz D, Walter J, Kirchhoff F, Hanisch UK, Kummer MP: Locus ceruleus controls Alzheimer's disease pathology by modulating microglial functions through norepinephrine. Proc Natl Acad Sci, USA 2010, 107:6058-6063.

55. Fuhrmann $M$, Bittner $T$, Jung $C K$, Burgold $S$, Page RM, Mitteregger $G$ Haass C, LaFerla FM, Kretzschmar H, Herms J: Microglial Cs3cr1 knockout prevents neuron loss in a mouse model of Alzheimer's disease. Nat Neurosci 2010, 13:411-413.

56. Lee $C Y$, Landreth GE: The role of microglia in amyloid clearance from the AD brain. J Neural Transm 2010, 117(8):949-60.

57. Rebaudo R, Melani R, Balestrino M, Cupello A, Haglid K, Hyden H: Antiserum against S-100 protein prevents long term potentiation through a cAMP-related mechanism. Neurochem Res 2000, 25:541-545.

58. Fulle S, Pietrangelo T, Mariggio MA, Lorenzon P, Racanicchi L, Mozizymas J Guarnieri S, Zuffoni-Grassi G, Fano G: Calcium and fos involvement in brain-derived $\mathrm{Ca}(2+)$-binding protein (S100)-dependent apoptosis in rat phaeochromacytoma cells. Exptl Physiol 2000, 85:243-253.

59. Hoppman S, Steinback J, Pietzsch J: Scavenger receptors are associated with cellular interaction of S100A12 in vitro and in vivo. Intl J Biochem Cell Biol 2010, 42:651-661.
60. Perrone $L$, Peulso $G$, Lenone M: RAGE recycles at the plasma membrane in S100B secretory vesicles and promotes Schwann cells morphological changes. J Cell Physiol 2008, 217:60-71.

61. Yan SD, Chen X, Fu J, Chen M, Zhu H, Roher A, Slattery T, Zhao L, Nagashima M, Morser J, Migheli A, Nawroth P, Stern D, Schmidt AM: RAGE and amyloid-beta peptide neurotoxicity in Alzheimer's disease. Nature 1996, 382:685-691.

62. Takeuchi M, Yamagishi S: Possible involvement of advanced glycation end-products (AGEs) in the pathogenesis of Alzheimer's disease. Curr Pharmaceut Design 2008, 14:973-978.

63. Deane R, Zlokovic BV: Role of the blood-brain-barrier in the pathogenesis of Alzheimer's disease. Curr Alzheimer Res 2007, 4:191-197.

64. Yan SD, Bierhaus A, Nawroth PP, Stern DM: RAGE and Alzheimer's disease: a progression factor for amyloid-beta-induced cellular perturbation. J Alzheimers Dis 2009, 16:833-843.

65. Steiner J, Walter M, Guest P, Myint AM, Schiltz K, Panteli B, Brauner M, Bernstein H-G, Gos T, Herberth M, Schroeter JL, Schwartz MJ, Westphal S, Bahn S, Bogerts B: Elevated S100B levels in schizophrenia are associated with insulin resistance. Mol Psychiatry 2010, 15:3-4.

66. Steiner J, Schroeter ML, Schiltz K, Bernstein H-G, Muller UJ, RichterLandsberg C, Muller WE, Walter M, Gos T, Bogerts B, Keilhoff G: Haloperidol and clozapine decrease S100B release from glial cells. Neurosci 2010, 167:1025-1031.

67. Pham N, Fazio V, Cucullo L, Teng Q, Biberthaler P, Bazarian JJ, Janigro D: Extracranial sources of S100B do not affect serum levels. PLoS One 2010, 5(9).

68. Shepherd CE, Goyette J, Utter V, Rahimi F, Geczy CL, Halliday GM: Inflammatory S100A9 and S100A12 proteins in alzheimer's disease. Neurobiol Aging 2006, 27:1554-1563.

69. Boom A, Pochet R, Authelet M, Pradier L, Borghgraef P, Van Leuven F, Heizmann CW, Brion J-P: Astrocytic calcium/zinc binding protein S100A6 over expression in alzheimer's disease and in PS1/APP transgenic mice models. Biochim Biophys Acta 2004, 1742:161-168.

70. Qin W, Ho L, Wang J, Peskink E, Pasinetti GM: S100A7, a novel alzheimer's disease biomarker with non-amyloidogenic alpha-secretase activity acts via selective promotion of ADAM-10. PLOS ONE 2009, 4:e4183.

71. Nedergaard M, Rodriguez JJ, Verkhratsky A: Glial calcium and disease of the nervous system. Cell Calcium 2010, 47:140-149.

72. Matute C: Calcium dyshomeostasis in white matter pathology. Cell Calcium 2010, 47:150-157.

doi:10.1186/1742-2094-7-78

Cite this article as: Roltsch et al:: PSAPP mice exhibit regionally selective reductions in gliosis and plaque deposition in response to $\mathrm{S100B}$ ablation. Journal of Neuroinflammation 2010 7:78.

\section{Submit your next manuscript to BioMed Central and take full advantage of:}

- Convenient online submission

- Thorough peer review

- No space constraints or color figure charges

- Immediate publication on acceptance

- Inclusion in PubMed, CAS, Scopus and Google Scholar

- Research which is freely available for redistribution

Submit your manuscript at www.biomedcentral.com/submit
C Biomed Central 